\title{
Educación remota en el contexto universitario: necesidad del trabajo colaborativo para la mediación pedagógica docente en tiempos de COVID
}

\author{
Remote education in the university context: necessary collaborative work for teaching \\ pedagogical mediation in the time of COVID
}

\section{Educação remota no contexto universitário: necesario trabalho colaborativo para mediação pedagógica educacional em tempos de COVID}

Virginia Cerdas-Montano

Universidad Nacional

ROR:: https://ror.org/01t466c14

Centro de Investigación y Docencia en Educación

División de Educación para el Trabajo

Heredia, Costa Rica

norma.cerdas.montano@una.cr

https://orcid.org/0000-0003-1705-4630

Álvaro Mora-Espinoza

Universidad Nacional

ROR:: https://ror.org/01t466c14

Centro de Investigación y Docencia en Educación

División de Educación para el Trabajo

Heredia, Costa Rica

alvaro.mora.espinoza@una.cr

https://orcid.org/0000-002-6145-0000

Silvia Elena Salas-Soto

Universidad Nacional

ROR:: https://ror.org/01t466c14

Centro de Investigación y Docencia en Educación

División de Educación para el Trabajo

Heredia, Costa Rica

silvia.salas.soto@una.cr

https://orcid.org/0000-0002-1629-140X

Resumen: La Comisión Curricular de la División de Educación para el Trabajo, asume la modalidad de educación remota a través del trabajo colaborativo, apoyando al cuerpo docente en el desarrollo de habilidades para procesos de enseñanza y aprendizaje requeridos.

Palabras claves: Educación; mediación pedagógica; trabajo colaborativo; cambio; COVID-19. 
https://doi.org/10.15359/ree.24-S.9

https://www.revistas.una.ac.cr/index.php/educare

educare@una.ac.cr

\begin{abstract}
The Curricular Commission of the Division of Education for Work. Assumes the modality of remote education through collaborative work, supporting the teaching staff in the development of required skills for the teaching and learning processes.
\end{abstract}

Keywords: Education; pedagogical mediation; collaborative work; change; COVID-19.

Resumo: A Comissão Curricular da Divisão de Educação para o Trabalho assume a modalidade de educação à distância por meio de trabalho colaborativo, apoiando o corpo docente no desenvolvimento de habilidades para os processos de ensino e aprendizagem necessários.

Palavras-chaves: Educação; mediação pedagógica; trabalho colaborativo; mudança; COVID-19.

Recibido: 15/07/2020 Aceptado: 07/08/2020

\title{
Introducción
}

La División de Educación para el Trabajo (DET) de la Universidad Nacional, Costa Rica, oferta las carreras de orientación, administración educativa y el posgrado de maestría en gestión educativa con énfasis en liderazgo. Con la aparición del virus COVID-19 en el país y ante los mandatos de las autoridades nacionales de salud, la Universidad Nacional (UNA) se ve en la imperante necesidad de hacer emergentemente todas las adaptaciones metodológicas a la academia, con el fin de resguardar tanto la integridad del estudiantado como de sus funcionarios y funcionarias. Por lo anterior, se instaura como medida esencialmente para la academia la implementación de la educación remota. Dicha modalidad refiere a la utilización prioritaria de herramientas tecnológicas, que favorezcan la educación a distancia, y de esta forma lograr los objetivos pedagógicos de cada plan de estudios. El abordaje que se plantea es integral, ya que la persona docente debe valorar las condiciones individuales del estudiantado y la naturaleza del curso, además de asumir su propia autocapacitación para el pleno desarrollo de habilidades y destrezas que se requieren en la utilización de los entornos virtuales.

En esta misma línea, la Comisión Curricular de la DET, impulsa un trabajo colaborativo para hacer frente a una implementación sostenible de dos rediseños curriculares que iniciaron en febrero de 2020 en las carreras de orientación y de administración educativa. Con este nuevo e inédito escenario, se generan una serie de desafíos y retos, pero también aprendizajes a través de varios meses de trabajo, que se convierten en el objetivo de este documento. En este sentido, planteamos un análisis reflexivo respecto del abordaje que se ha hecho en la DET, ante las vicisitudes que plantea el manejo de la pandemia, en cuanto a la eficiencia de esta modalidad de educación remota. 
https://doi.org/10.15359/ree.24-S.9

\section{Desarrollo}

La mediación pedagógica como un acto intencionado de comunicación, cargado de significados en el proceso de enseñanza y aprendizaje (Alzate-Ortiz y Castañeda-Patiño, 2020), requiere de una reflexión permanente, ya que cada contexto conlleva sus propios desafíos.

Enfrentarse a una pandemia constituye un elemento de extraordinarios retos académicos para la mediación pedagógica en el contexto principalmente universitario, toda vezquelos efectos en la salud que supondría la presencialidad y sus riesgos afectan la entrega de la docencia que tradicionalmente ha tenido nuestra casa de enseñanza. Es por ello que la Comisión Curricular, dentro de sus funciones busca constantemente alternativas de coadyuvar al cuerpo docente, en aras del apoyo institucional, ante personal con manifestaciones de cansancio, falta de capacitación y sobre todo agobio por la cantidad de información que emana de las autoridades de la Universidad para realizar adaptaciones metodológicas a los cursos en ejecución. Se plantean desafíos concretos ante la respuesta inmediata que debe dar la docencia al estudiantado, el cual también requiere de una orientación mayor en estos procesos adaptativos a una nueva y emergente situación. Sin embargo, esta inmediatez, viene en algunas ocasiones a atentar contra la privacidad del personal docente, en sus espacios privados, de descanso y de su necesaria tranquilidad en su vida personal, aunado a otras múltiples ocupaciones que pueda tener. Esta situación pone de manifiesto limitaciones de la capacidad crítica y comprensiva que necesariamente se debe favorecer en los procesos de aprendizaje.

Es aquí donde el trabajo colaborativo se hace -a nuestro modo de ver- imprescindible, ya que la integración de liderazgos pedagógicos y de la riqueza experiencial, cada docente (Rojas Carrasco et al., 2020), favorece integralmente los procesos de formación, de cara al compromiso que tendrán que asumir las futuras personas profesionales para generar una transformación social desde marcos éticos y de resiliencia. Desde esta perspectiva se requiere afianzar el optimismo; asumir estos tiempos de incertidumbre como una oportunidad más de aprendizaje, de capacidad para desarrollar nuevas competencias y habilidades. La educación es un proceso constante y permanente, por tanto, se aprende y se desarrollan capacidades para enfrentar con responsabilidad los cambios que demanda la realidad presente; valentía, enfrentar con valor las transformaciones societarias, impregnando de entusiasmo la academia; equidad, para tratar al estudiantado con respeto, valorando a cada quien en su individualidad y particularidad; y compromiso, toda vez que la educación es una tarea de vocación.

La sociedad mundial nunca ha estado más de frente -y en particular nuestra Institución- a la innovación pedagógica, que exigen estos meses de pandemia. Tal y como lo señala Moreno-Correa (2020), en lo intrínseco del trabajo que se debe emprender, es posible derribar muros, anular mitos y generar la motivación suficiente para reconocer la solidaridad y la colaboración espontánea entre personas encargadas de la entrega a la docencia. De allí que el trabajo colaborativo se impone como una necesidad, ya que en este proceso cada participante aprende más de lo que aprendería por sí solo y la interacción con los demás aprendientes, enriquece significativamente 
https://doi.org/10.15359/ree.24-S.9

https://www.revistas.una.ac.cr/index.php/educare

educare@una.ac.cr

dicho aprendizaje, liberando y compartiendo la carga que suponen los retos y desafíos aludidos. El trabajo colaborativo persigue objetivos comunes, en este caso respecto del proceso de enseñanza y aprendizaje, cuál es su mejor ejecución; por ende, se construye un proyecto colectivo.

\section{Conclusiones}

Las adaptaciones abruptas que imperan en la implementación de un proceso atípico definitivamente requieren de mucha flexibilidad y comprensión académica. Es claro que no se pueden obtener los mismos resultados que hasta el momento la academia estaba acostumbrada. La adaptación al cambio debe ser una reflexión permanente y descubrir constantemente que estos cambios ofrecen otras oportunidades para el autoaprendizaje, para el trabajo autónomo y principalmente colaborativo, en donde la academia tenga claro el proyecto en común.

Definitivamente no existe una única forma o estilo de planificar, de ejecutar y guiar los procesos de enseñanza y aprendizaje. No hay recetas prestablecidas, ni garantías respecto de las adaptaciones metodológicas que se propongan, solo mejores experiencias, mejores prácticas, que, mediados por el trabajo colaborativo y la oportunidad de crecimiento colectivo entre equipos, permita compartir estrategias pedagógicas y didácticas, para ser aplicadas individualmente por la academia, contribuyendo de esta manera a mejorar la calidad de vida, tanto del cuerpo docente como del estudiantado en general.

Una respuesta oportuna al cambio, demanda establecer límites racionales de espacio y tiempo precisos para todas las personas participantes. En este nuevo escenario de aprendizaje y gestión pedagógica, es significativo aprovechar los espacios de interacción para el fomento de valores, la gestión de las inequidades y el respeto a la diversidad, a todo nivel del colectivo universitario.

Nota general: Corrección de estilo y traducciones a cargo de las personas autoras.

\section{Referencias}

Alzate-Ortiz, F. A.y Castañeda-Patiño, J.C. (2020). Mediación pedagógica: Clave de una educación humanizante y transformadora. Una mirada desde la estética y la comunicación. Revista Electrónica Educare, 24(1), 1-14. https://doi.org/10.15359/ree.24-1.21

Moreno-Correa S. M. (2020). La innovación educativa en los tiempos del Coronavirus. Salutem

Scientia Spiritus 2020, 6(1),14-26. https://revistas.javerianacali.edu.co/index.php/ salutemscientiaspiritus/article/view/2290/2863

Rojas Carrasco, O. A., Vivas Escalante, A. D., Mota Suárez, K. T. y Quiñonez Fuentes, J. Z. (2020). El liderazgo transformacional desde la perspectiva de la pedagogía humanista. Sophía, 28, 237-262. https://doi.org/10.17163/soph.n28.2020.09 